\title{
Klasifikasi Citra Warna Daun Padi Menggunakan Metode Histogram of S-RGB dan Fuzzy Logic Berbasis Android
}

\author{
Raimundus Sedo ${ }^{1)}$, Panca Mudjirahardjo ${ }^{2)}$, Erni Yudaningtyas ${ }^{3)}$ \\ ${ }^{I}$ Mahasiswa Program Studi Magister Teknik Elektro, Fakultas Teknik, Universitas Brawijaya Malang \\ ${ }^{2}$ Dosen Jurusan Teknik Elektro, Fakultas Teknik Universitas Brawijaya Malang
}

\section{KEYWORDS \\ Histogram of s-RGB, Fuzzy Logic, Bagan Warna Daun, Confusion Matrix for Multiple Classes}

\section{CORRESPONDENCE}

Phone: +62 (0751) 12345678

E-mail: rai_mun@yahoo.com

\section{PENDAHULUAN}

Nitrogen merupakan salah satu unsur hara terpenting yang sangat dibutuhkan setiap tanaman, terutama tanaman padi untuk pertumbuhan vegetatif pada tanaman tersebut [1]. Untuk itu, pemberian pupuk nitrogen secara seimbang pada tanaman padi perlu diperhatikan agar pertumbuhan tanaman tetap normal sehingga produktivitasnya menjadi lebih optimal.

Bagan Warna Daun (BWD) merupakan salah satu alat bantu yang telah direkomendasikan penggunaannya untuk dapat mengetahui kebutuhan nitrogen bagi tanaman padi [2]. Penggunaan BWD dilakukan secara visual dengan cara DOI: https://doi.org/10.30743/infotekjar.v3i2.1060

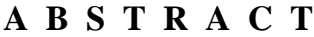

Tingkat kehijauan daun tanaman padi merupakan salah satu indikator untuk menganalisis kebutuhan unsur hara nitrogen yang diperlukan tanaman padi. Dalam perkembangannya, salah satu cara yang direkomendasikan untuk menentukan kebutuhan nitrogen bagi tanaman padi adalah penggunaan Bagan Warna Daun (BWD). Mengingat perlu adanya efisiensi waktu dan tenaga, serta untuk mengindari perbedaan presepsi terhadap warna yang diamati, maka penting untuk dilakukan pengembangan suatu sistem agar memudahkan para petani dalam menentukan kebutuhan nitrogen bagi tanaman padi.

Penelitian ini bertujuan untuk mengembangkan suatu sistem berbasis android untuk menentukan kebutuhan nitrogen bagi tanaman padi melalui konsep pengolahan citra. Metode yang digunakan adalah Histogram of $s-R G B$ dan Fuzzy Logic. Metode Histogram of $s-R G B$ berfungsi untuk mengekstraksi ciri warna daun padi, sedangkan Fuzzy Logic digunakan untuk mengklasifikasi citra daun padi berdasarkan 4 level warna pada BWD sekaligus menentukan dosis kebutuhan nitrogen yang diperlukan bagi tanaman padi.

Pengujian dilakukan menggunakan smartphone merk Samsung dengan kapasitas kamera 8 MP. Hasil pengujian dan evaluasi sistem menggunakan Confusion Matrix for Multiple Classes menunjukkan bahwa ketepatan sistem memberikan informasi yang diminta dinilai cukup baik, yaitu $88.19 \%$. Keberhasilan sistem untuk menemukan informasi kembali dengan tingkat recall sebesar $88.25 \%$. Tingkat kedekatan antara nilai prediksi sistem dengan nilai aktual sebesar $88.75 \%$, serta tingkat specificity yang diperoleh sebesar $62.12 \%$. Sedangkan waktu komputasi sistem yang dicapai rata-rata 10.14 detik.

membandingkan level warna pada BWD terhadap warna daun padi. Cara ini dinilai kurang efisien karena dapat menghabiskan banyak waktu dan tenaga dalam pelaksanaannya. Selain itu, proses membandingkan warna tersebut masih dilakukan secara visual (manual) menggunakan mata tanpa alat bantu sehingga dapat memberikan presepsi yang berbeda di antara setiap pengguna, khususnya para petani sehingga hasil yang diperoleh juga dapat bervariasi.

Penelitian sebelumnya telah mengembangkan suatu aplikasi mobile berbasis android untuk memperkirakan status nitrogen pada tanaman padi dengan menggunakan 6 skala BWD [3]. Namun, proses akuisisi citra masih dilakukan dalam kondisi ruangan terbuka dengan intensitas cahaya yang berbeda 
sehingga hasilnya dapat berubah-ubah. Penelitian lainnya tentang pengukuran tingkat warna daun padi dan takaran pemupukan menggunakan Artificial Neural Network (ANN) dan $k$-Nearest Neighborhood (kNN) [4]. Pada penelitian tersebut, database sistem yang telah dirancang hanya dibatasi pada smartphone tertentu sehingga tidak dapat dimanfaatkan pada smartphone yang lain.

Penelitian ini bertujuan untuk menerapkan metode Histogram of $s-R G B$ dan Fuzzy Logic untuk dapat menganalisis kebutuhan pupuk nitrogen sebagai unsur hara bagi tanaman padi berdasarkan tingkat kehijauan daun padi berbasis android.

Berdasarkan hasil penelitian [5], diketahui bahwa metode Histogram of $s-R G B$ cocok untuk diterapkan pada aplikasi real time karena dapat mendeteksi latar belakang dengan waktu komputasi yang relatif singkat. Pada penelitian ini, metode Histogram of $s-R G B$ digunakan untuk mengekstraksi ciri warna daun padi sehingga menghasilkan output berupa nilai modus $R$ (Red), G (Green), dan B (Blue). Output yang telah diperoleh tersebut kemudian diolah menggunakan fuzzy logic pada tahap klasifikasi untuk menentukan takaran pupuk nitrogen yang dibutuhkan tanaman padi.

\section{METODELOGI}

\section{Konsep Histogram of $s-R G B$}

Histogram of $s-R G B$ merupakan salah satu metode yang cocok untuk diterapkan pada aplikasi real time karena dapat mendeteksi latar belakang dengan waktu komputasi yang relatif singkat. Langkah pertama algoritma Histogram of $s-R G B$ adalah menghitung jumlah intensitas RGB $(s-R G B)$ pada setiap piksel [5].

Perhitungan dapat dilakukan menggunakan persamaan sebagai berikut.

$$
s-R G B(x, y)=I_{R}(x, y)+I_{G}(x, y)+I_{B}(x, y)
$$

dimana $s-R G B(\mathrm{x}, \mathrm{y})$ adalah jumlah dari intensitas $R G B$ pada piksel $(x, y), I_{R}(x, y), I_{G}(x, y)$, dan $I_{B}(x, y)$ adalah merah, hijau dan intensitas biru di masing-masing piksel $(\mathrm{x}, \mathrm{y})$. Ketika menggunakan 8 bit untuk kode intensitas warna, maka mendapatkan nilai $s-R G B$ dari 0-765. Selanjutnya menentukan modus determinan biner dengan persamaan berikut ini.

$$
\bmod _{s-R G B}=\underset{\text { bin }}{\arg \max }(\text { histogram of } s-R G B)
$$

Setelah mendapatkan nilai modus, untuk setiap piksel yang memiliki nilai $s-R G B$ dalam bin modus akan diproses untuk membuat histogram dari intensitas untuk setiap intensitas $R G B$. Histogram ini menunjukkan frekuensi kemunculan intensitas warna. Untuk menentukan warna dominan dalam modus bin yaitu menghitung modus warna dari masing-masing histogram dari intensitas seperti persamaan berikut ini.

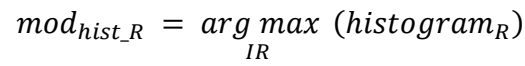

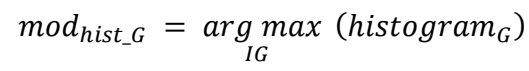

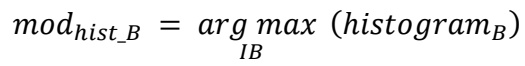

Selanjutnya dominan warna $\left(\bmod _{R G B}\right)$ tersebut, dapat dihitung menggunakan persamaan berikut ini.

$$
\bmod _{R G B}=\max \left(\bmod _{\text {hist_R }}, \bmod _{\text {hist_G }}, \bmod _{\text {hist_B }}\right)(6)
$$

\section{Konsep Fuzzy Logic}

Fuzzy logic merupakan logika yang dapat menjelaskan fenomena atau proses tertentu secara linguistik, kemudian mempresentasikannya dalam sejumlah kecil aturan yang fleksibel dan menyediakan solusi bagi masalah-masalah yang sulit dipecahkan menggunakan aturan If-Then. Fuzzy Logic telah memungkinkan perubahan secara bertahap pada masukan dan menghasilkan perubahan yang mulus pada keluaran, serta bukan keluaran yang putus-putus [6]. Untuk itu, keanggotaan dalam himpunan fuzzy bukan merupakan sesuatu yang tegas (yaitu anggota atau bukan anggota), melainkan sesuatu yang berderajat atau bergradasi secara kontinu [7]. Komponen fuzzy logic secara garis besar, meliputi himpunan fuzzy, fungsi keanggotaan, fuzzifikasi, inferencing (Rule Base), dan defuzzifikasi. Pada penelitian ini, model penalara fuzzy yang digunakan adalah fuzzy model Sugeno Orde Nol yang menghasilkan output (konsekuen) sistem tidak berupa himpunan fuzzy, melainkan berupa konstanta atau persamaan linear sehingga model aturan yang terbentuk [8], yaitu :

If (Red is A) AND (Green is B) AND (Blue is C) then $Z=$ $f($ Red,Green,Blue)

dengan Red, Green, Blue adalah himpunan fuzzy dalam antecedent dan adalah fungsi tegas dalam konsekuensi.

\section{Konsep Android}

Android adalah sistem operasi untuk telepon seluler berbasis linux. Android menyediakan platform terbuka bagi para pengembang untuk menciptakan aplikasinya sendiri untuk digunakan oleh bermacam-macam piranti bergerak. Keunggulan android adalah bersifat open source karena berbasis linux yang dapat dikembangkan [9]. Arsitektur android secara garis besar terdiri atas applications dan widgets, applications frameworks, libraries, android run time, dan linux kernel [10].

\section{Bagan Warna Daun (BWD)}

Bagan warna daun (BWD) adalah alat berbentuk persegi empat yang berguna untuk mengetahui status hara nitrogen pada tanaman padi. BWD diadopsi oleh International Rice Research Institute (IRRI)[11] dan direkomendasikan penggunaannya oleh pemerintah agar pemupukan lebih efisien dan produksi optimal [2]. Tampilan BWD tertera pada Gambar 1 dan Gambar 2.

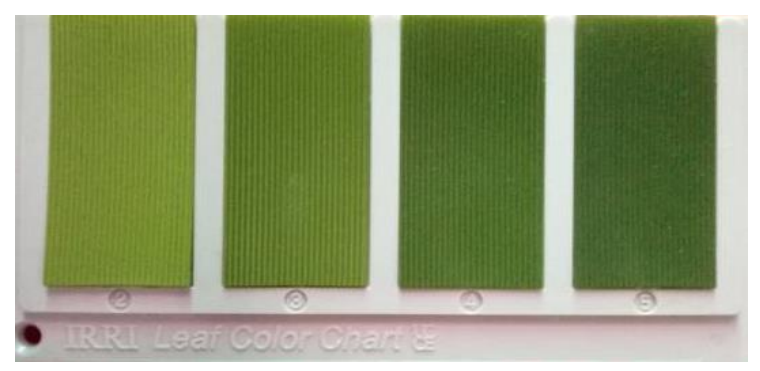

Gambar. 1. Bagan Warna Daun (BWD) 


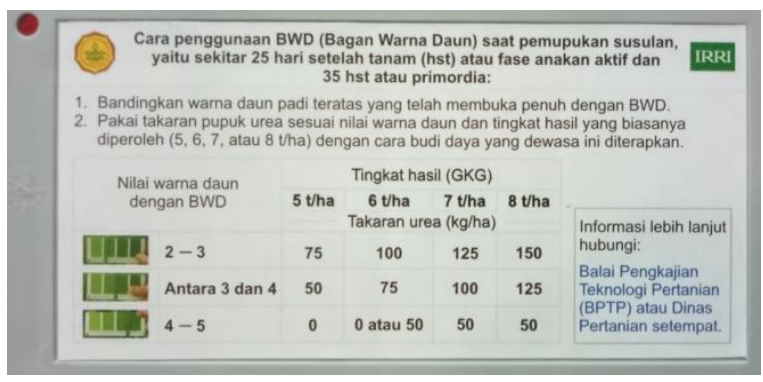

Gambar. 2. Rekomendasi pemberian pupuk nitrogen (N)

\section{Data Penelitian}

Data sampel yang digunakan sejumlah 80 data citra daun padi yang diambil berdasarkan rekomendasi dari Pusat Penelitian dan Pengembangan Tanaman Pangan Republik Indonesia, yaitu pertumbuhan tanaman padi sekitar 25 hari setelah tanam (HST) atau fase anakan aktif dan 35 hari setelah tanam (HST) atau primordia. Proses pengambilan sampel dilakukan dengan cara membandingkan level warna pada BWD terhadap warna daun padi yang dilakukan secara visual.

\section{Alat dan Bahan}

1. Kebutuhan perangkat keras

Spesifikasi hardware atau perangkat keras yang dibutuhkan, meliputi :

a. Satu unit komputer (laptop) merk Toshiba model Satellite C600, Processor Intel (R) Core (TM)2 Duo CPU, dan RAM 4096 MB, serta 1 unit printer.

b. Smartphone dan kabel data serta alat lux meter pengukur intensitas cahaya

c. Alat uji citra dengan intensitas cahaya konstan (constant lux box)

2. Kebutuhan perangkat lunak

Kebutuhan perangkat lunak dalam penelitian adalah sebagai berikut.

a. Sistem Operasi Microsoft Windows 7.

b. Android Studio digunakan untuk pembuatan program.

c. Microsoft Visio 2013 digunakan dalam pembuatan flowchart sistem.

3. Kebutuhan bahan

Bahan yang dibutuhkan dalam penelitian ini adalah sebagai berikut.

a. Bagan Warna Daun (BWD)

b. Data takaran pupuk nitrogen untuk tanaman padi

\section{Peracangan Sistem}

Perancangan sistem pada penelitian ini dapat diuraikan sebagai berikut.

\section{Akuisisi Citra}

Data ctra daun padi yang digunakan sejumlah 80 citra. Proses akuisisi citra dilakukan dengan menggunakan smartphone merk Samsung J3 2016 dengan kapasitas kamera 8 MP. Citra daun padi diletakkan di dalam constant lux box yang dirancang sebagai studio mini sehingga intensitas cahaya diharapkan konstan saat proses akuisisi citra. Tipe file yang dihasilkan yaitu JPEG (Joint Photographic Expert in Group).

\section{Preprocessing}

Proses cropping dan resizing citra daun padi dilakukan pada tahap ini untuk memperoleh wilayah citra daun dengan ukuran 50x50 piksel yang digunakan sebagai parameter warna daun untuk setiap sampel citra daun padi.

\section{Ekstraksi Ciri Warna}

Ekstraksi ciri warna daun padi dianalisis menggunakan metode Histogram of $s$-RGB. Adapun flowchart algoritma Histogram of $s-R G B$ tertera pada Gambar 3.

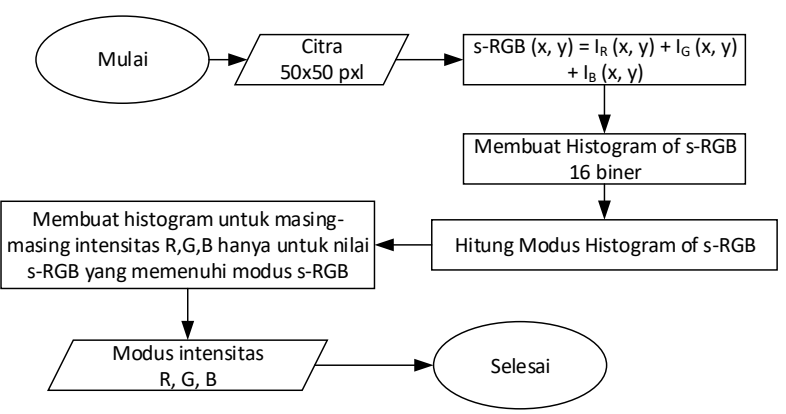

Gambar. 3. Flowchart Histogram of $s-R G B$

Untuk menentukan modus determinan biner dengan persamaan (2). Untuk menghitung modus warna dari masingmasing histogram dari intensitas seperti persamaan (3), persamaan (4), dan persamaan (5). Sedangkan, untuk menghitung dominan warna $\left(\bmod _{R G B}\right)$ menggunakan persamaan (6).

\section{Klasifikasi}

Metode yang digunakan pada tahap klasifikasi adalah fuzzy logic. Adapun flowcahart fuzzy logic diperlihatkan pada Gambar 4.

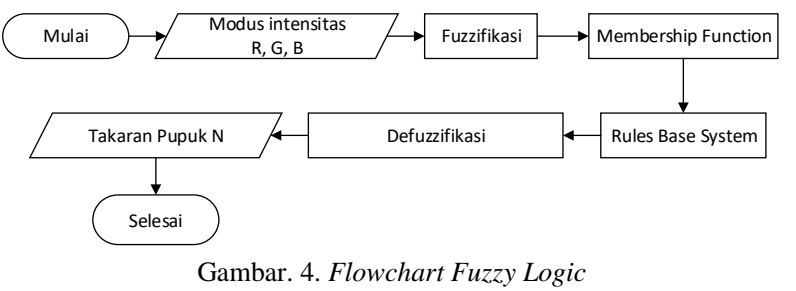

Parameter input fuzzy logic sebanyak 3 variabel input, yaitu nilai hist_R, hist_G, dan hist_B. Setiap variabel terbagi dalam 3 himpunan keanggotaan untuk setiap variabel, yaitu himpunan rendah, sedang, dan tinggi. Fungsi keanggotaan fuzzy logic direpresentasikan dalam bentuk kurva segitiga dan kurva bahu [8].

Proses penentuan aturan fuzzy diawali dengan penentuan nilai output sebagai target. Output tersebut berupa nilai RGB pada masing-masing level warna BWD menggunakan skala range variabel berkisar $0-100$. Sedangkan, tahap defuzifikasi menggunakan logika fuzzy model sugeno orde-nol [8]. Contoh model aturan yang terbentuk, yaitu :

If (Red is rendah)AND(Green is rendah)AND(Blue is rendah)then $Z=B W D 5$ 


\section{Pengujian Sistem}

Proses pengujian sistem dilakukan dengan cara membandingkan hasil klasifikasi level warna BWD kelaran sistem terhadap hasil klasifikasi BWD berdasarkan pengamatan secara visual. Hasilnya dapat dievaluasi menggunakan Confusion Matrix for Multiple Classes dengan rumus [12] :

Precision $=\frac{\sum_{i=1}^{l} T P i}{\sum_{i=1}^{l} T P i+F P i} \times 100 \%$

Sensitivity $($ Recall $)=\frac{\sum_{i=1}^{l} T P i}{\sum_{i=1}^{l} T P i+F N i} 100 \%$

Sensitivity $($ Recall $)=\frac{\sum_{i=1}^{l} T N i}{\sum_{i=1}^{l} T N i+F P i} 100 \%$

Accuracy $=\sum_{i=1}^{l} \frac{T P i+T N i}{T P i+T N i+F P i+F N i} \times 100 \%$

\section{HASIL DAN PEMBAHASAN}

\section{Hasil Klasifikasi Secara Visual Menggunakan Bagan} Warna Daun (BWD)

Berdasarkan hasil pengamatan secara visual yang dilakukan dengan cara membandingkan level warna pada BWD terhadap warna pada citra daun padi, maka diperoleh hasil sebagaimana tertera pada Tabel 4.1 sebagai berkut.

Tabel 1

Hasil klasifikasi level bwd secara visual

\begin{tabular}{cc}
\hline \hline Data Citra & Hasil Visual \\
\hline C_1 & Level 4 \\
C_2 & Level 4 \\
C_3 & Level 3 \\
C_4 & Level 2 \\
C_5 & Level 2 \\
C_6 & Level 5 \\
C_7 & Level 5 \\
C_8 & Level 3 \\
C_9 & Level 5 \\
C_10 & Level 4 \\
........ & ....... \\
C_80 & Level 5 \\
\hline \hline
\end{tabular}

\section{Hasil Klasifikasi Sistem}

Alur kerja sistem dimulai dengan proses akuisisi citra daun padi yang diletakkan di dalam constant lux box (studio mini). Smartphone yang digunakan adalah smartphone merk Samsung J3 2016 degan kapasitas kamera 8 MP. Kemudian citra daun tersebut dilakukan cropping dan resizing menjadi ukuran 50x50 piksel. Selanjutnya diekstraksi ciri warna daun padi tersebut menggunakan metode Histogram of $s-R G B$ sehingga menghasilkan output berupa nilai modus $R$ (Red), $G$ (Green), dan $B$ (Blue). Output yang telah diperoleh kemudian diolah menggunakan fuzzy logic pada tahap diklasifikasi. Tampilan constant lux box tertera pada Gambar 5, sedangkan hasil preprocessing diperlihatkan pada Gambar 6 sebagai berikut.

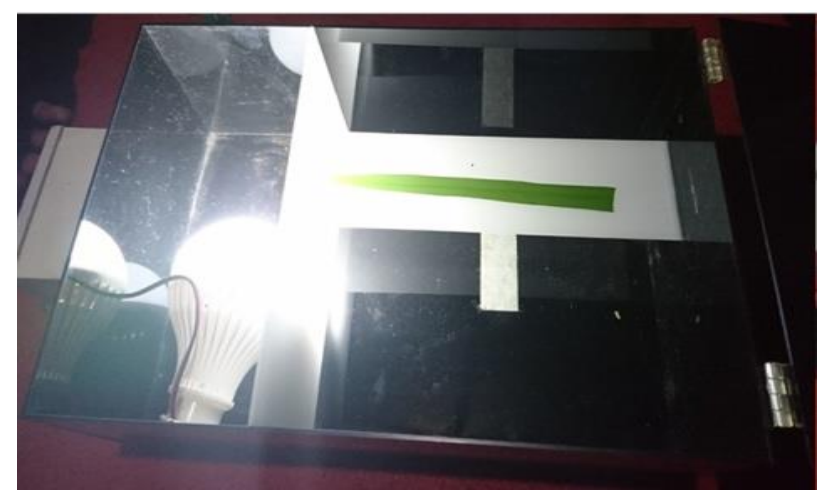

Gambar. 5. Tampilan constant lux box

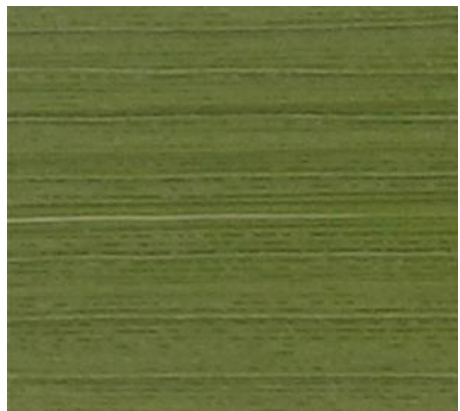

Gambar 6. Contoh hasil preprocessing citra daun padi 50x50 piksel

\section{Hasil Ekstraksi Ciri Warna}

Contoh hasil ekstraksi ciri warna citra daun padi yang dilakukan sistem menggunakan metode Histogram of $s-R G B$ tertera pada Gambar 7 dan Gambar 8 serta Tabel 2 dan 3.

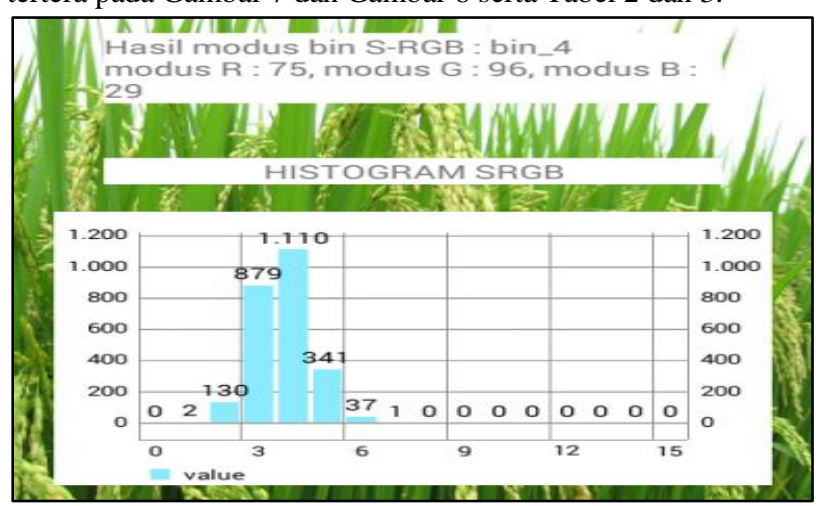

Gambar 7. Histogram s-RGB pada smartphone $8 \mathrm{MP}$

Berdasarkan Gambar 7, dapat diketahui bahwa hasil pengujian sistem pada smartphone $8 \mathrm{MP}$ menghasilkan nilai modus $s$ - $R G B$ terletak di bin $(4=1110)$, dengan nilai mod_R $=75$, mod_G $=96$, dan mod_B=29.

Tabel 2

Histogram s-rgb pada smartphone $8 \mathrm{mp}$

\begin{tabular}{cccc}
\hline \hline Data & \multicolumn{3}{c}{ Smartphone 8 MP } \\
\cline { 2 - 4 } Citra & Mod_R & Mod_G & Mod_B \\
\hline C_1 & 75 & 96 & 29 \\
C_2 & 64 & 104 & 38 \\
C_3 & 94 & 124 & 38 \\
C_4 & 116 & 142 & 38 \\
$\ldots$ & $\ldots$ & $\ldots$ & $\ldots$ \\
C_80 & 49 & 72 & 32 \\
\hline \hline
\end{tabular}


Hasil yang diperoleh sebagaimana tertera pada Gambar 7 menunjukkan bahwa distribusi citra yang dihasilkan dinilai cukup baik karena memiliki histogram yang mengisi daerah derajat keabuan dan terdistribusi secara merata pada masingmasing nilai intensitas piksel.

\section{Hasil Klasifikasi}

Contoh hasil klasifikasi dengan menggunakan fuzzy logic diperlihatkan pada Gambar 8 Tabel 3.

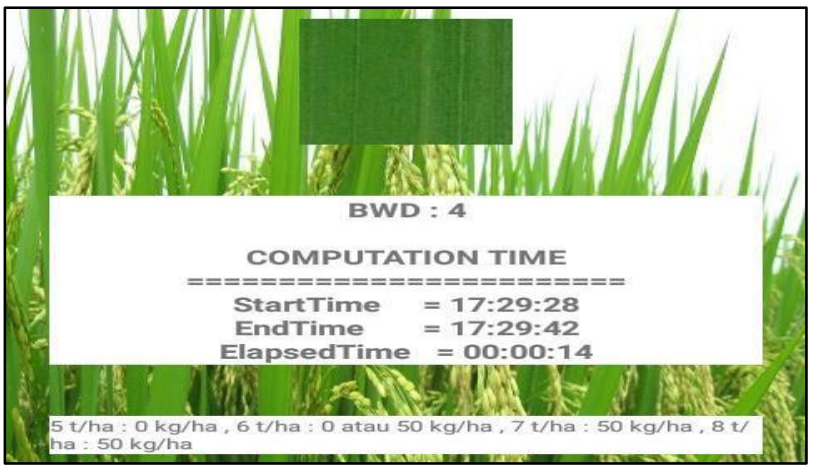

Gambar. 8. Tampilan hasil klasifikasi level BWD Fuzzy Logic

Tabel 3

Hasil klasifikasi sistem

\begin{tabular}{ccc}
\hline \hline \multirow{2}{*}{ Data Citra } & \multicolumn{2}{c}{ Hasil Klasifikasi Sistem } \\
\cline { 2 - 3 } & Level BWD & $\begin{array}{c}\text { Elapsed Time } \\
\text { (Second) }\end{array}$ \\
\hline C_1 & Level 4 & $\mathbf{1 4 s}$ \\
C_2 & Level 3 & $\mathbf{1 3 s}$ \\
C_3 & Level 3 & $\mathbf{8 s}$ \\
C_4 & Level 2 & $\mathbf{1 2 s}$ \\
$\ldots \ldots$ & $\ldots .$. & $\ldots .$. \\
C_80 & Level 5 & $\mathbf{6 s}$ \\
\hline Rata-rata & & $\mathbf{1 0 . 1 3 7 s}$ \\
\hline \hline
\end{tabular}

Berdasarkan Tabel 3 dan Gambar 8, diketahui bahwa ratarata elapsed time sistem 10.137 s,

\section{Hasil Pengujian Sistem}

Pengujian sistem dilakukan dengan cara membandingkan hasil klasifikasi level warna BWD keluaran sistem terhadap hasil klasifikasi BWD berdasarkan pengamatan secara visual yang dievaluasi menggunakan Confusion Matrix for Multiple Classes dengan rumus [11]. Evaluasi sistem perlu dlakukan untuk mengetahui performa kerja sistem secara keseluruhan. Contoh hasil klasifikasi secara visual menggunakan BWD dan hasil klasifikasi oleh sistem tertera pada Tabel 4.
Tabel 4

Hasil klasifikasi level bwd dengan oleh sistem dan hasil secara visual

\begin{tabular}{ccc}
\hline \hline $\begin{array}{c}\text { Data } \\
\text { Citra }\end{array}$ & Hasil Sistem & Hasil Visual \\
\hline C_1 & Level 4 & Level 4 \\
C_2 & Level 3 & Level 4 \\
C_3 & Level 3 & Level 3 \\
C_4 & Level 2 & Level 2 \\
C_5 & Level 2 & Level 2 \\
C_6 & Level 5 & Level 5 \\
C_7 & Level 5 & Level 5 \\
C_8 & Level 2 & Level 3 \\
C_9 & Level 5 & Level 5 \\
C_10 & Level 4 & Level 4 \\
$\ldots \ldots \ldots \ldots$. & $\ldots \ldots .$. & $\ldots . . .$. \\
C_80 & Level 5 & Level 5 \\
\hline \hline
\end{tabular}

Tahap selanjutnya adalah mengevaluasi performa kinerja sistem dengan menggunakan Confusion Matrix for Multiple Classes untuk menguji presisi, sensivicity, specificity dan overall accuracy sistem. Hasil evaluasi tertera pada Tabel 5 dan Gambar.

Tabel 5

Hasil evaluasi sistem

\begin{tabular}{lcccc}
\hline \hline \multicolumn{1}{c}{ Ket. } & $\begin{array}{c}\text { Precision } \\
(\%)\end{array}$ & $\begin{array}{c}\text { Recall } \\
(\%)\end{array}$ & $\begin{array}{c}\text { Specificity } \\
(\%)\end{array}$ & $\begin{array}{c}\text { Overall Accuracy } \\
(\%)\end{array}$ \\
\hline BWD $_{\text {L-2 }}$ & 91.67 & 95,65 & 75.00 & \\
BWD $_{\text {L-3 }}$ & 86.36 & 82.61 & 40.00 & \\
BWD $_{\text {L-4 }}$ & 80.00 & 80.00 & 50.00 & \multirow{2}{*}{88.75} \\
BWD $_{\text {L-5 }}$ & 94.74 & 94.74 & 87.50 & \\
\hline Rata-rata & $\mathbf{8 8 . 1 9}$ & $\mathbf{8 8 . 2 5}$ & $\mathbf{6 3 . 1 2}$ & \\
\hline \hline
\end{tabular}

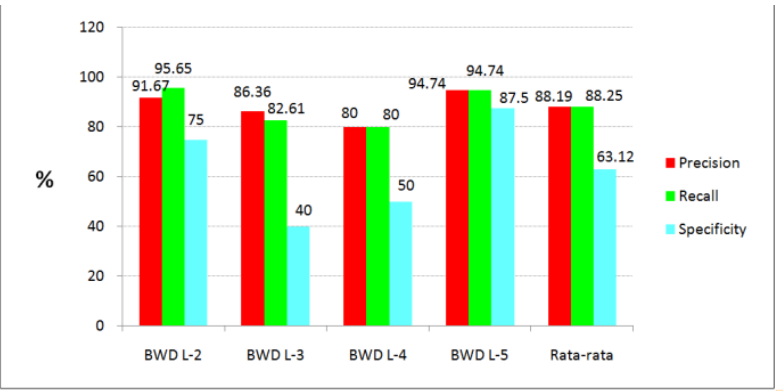

Gambar. 9. Grafik evaluasi pada smartphone $8 \mathrm{MP}$

Tabel 5 dan Gambar 9 menunjukkan bahwa rata-rata precision sistem pada smartphone 8 MP sebesar $88.19 \%$. Hal ini berarti sistem secara tepat memberikan informasi yang diminta dengan tingkat presisi sekitar $88.19 \%$. Tingkat kedekatan antara nilai prediksi oleh sistem dengan nilai aktual dikategorikan cukup tinggi yang ditunjukkan dengan nilai akurasi sekitar $88.75 \%$. Selain itu, tingkat keberhasilan sistem untuk menemukan informasi kembali dinilai cukup baik yang dengan tingkat recall sebesar $88.25 \%$, sedangkan tingkat specificity $63.12 \%$. 


\section{PENUTUP}

\section{Simpulan}

Berdasarkan hasil pengujian dan analisis sistem, maka dapat diberikan beberapa kesimpulan sebagai berikut.

1. Sistem mampu mengekstraksi ciri warna citra daun padi dan mengklasifikasikan citra daun padi tersebut berdasarkan level warna BWD menggunakan kombinasi metode Histogram of $s-R G B$ dan Fuzzy Logic.

2. Hasil pengujian dan evaluasi system menunjukkan bahwa sistem secara tepat memberikan informasi yang diminta dengan rata-rata tingkat presisi sekitar $88.19 \%$. Tingkat kedekatan antara nilai prediksi oleh sistem dengan nilai aktual ditunjukkan dengan nilai akurasi sekitar $88.75 \%$. Tingkat keberhasilan sistem untuk menemukan informasi dengan tingkat recall sebesar $88.25 \%$, sedangkan tingkat specificity $63.12 \%$.

3. Komputasi waktu yang dihasilkan sistem rata-rata mencapai 10.14 detik.

\section{Saran}

Saran yang diharapkan untuk pengembangan penelitian selanjutnya adalah sebagai berikut.

1. Penelitian selanjutnya dapat dilakukan untuk menganalisis kandungan unsur hara nitrogen yang dibutuhkan pada tanaman lain, seperti tanaman jagung.

2. Perlu dilakukan pengujian pada smartphone dengan merk dan kapasitas kamera yang berbeda-beda untuk proses perbandingan.

\section{REFERENCES}

[1] Firmansyah, I \& Sumarni, N. (2013). Effect of N Fertilizer Dosages and Varieties On Soil pH, Soil Total-N, N Uptake, and Yield of Shallots (Allium ascalonicum L). Varieties On Entisols-Brebes Central Java. J. Hort. Vol. 23. No. 4. h. 357-364.

[2] Permentan Republik Indonesia. (2016). Acuan Penetapan Rekomendasi Pemupukan N, P, dan K Pada Padi Sawah Spesifik Lokasi (Per Kecamatan) : Sebagai Lampiran Dari Permentan No.40/Permentan/OT.140/4/2007tentang Rekomendasi Pemupukan N, P, dan K Pada Padi Sawah Spesifik Lokasi. Jakarta : Kementerian pertanian Republik Indonesia.

[3] Kaur, N \& Singh, D. (2016). Android Based Mobile Application to Estimate Nitrogen Content in Rice Crop. International Journal of Computer Trends and Technology (IJCTT).Volume 38 No.2. ISSN: 2231-2803.pp.87-91.

[4] Astika, I, W, Sugiyanta, \& Cibro, M, M. (2012). Pengukuran Tingkat Warna Daun Padi dan Dosis Pemupukan Dengan Telepon Seluler Android. Prosiding InSINas 2012. h. 43-49.

[5] Mudjirahardjo, P, Nurussa'adah \& Siwindarto, P. (2016). Soccer Field Detection on Histogram of $s-R G B$. ARPN Journal of Engineering and Applied Sciences. ISSN 1819-6608. Vol. 11. No. 21. pp.12405-12408.

[6] Laudon, K, C \& Laudon, J, P. (2008). Sistem Informasi Manajemen : Mengelola Perusahaan Digital. Edisi 10. Buku 2. Jakarta : Salemba Empat.
[7] Yazdi, M. (2014). Pemrograman Matlab Pada Sistem Pakar Fuzzy : Kasus Menentukan dan Mengukur Suatu Kinerja. Yogyakarta : Deepublish.

[8] Widodo, T, S. (2005). Sistem Neuro Fuzzy Untuk Pengolahan Informasi, Pemodelan, dan Kendali. Yogyakarta : Graha Ilmu.

[9] Azis, S. (2012). All About Android : Cukup Satu Buku Untuk Menjelajahi Dunia Android. Jakarta : Kuncikom.

[10] Supardi, Y. (2014). Semua Bisa Menjadi Programmer Case Study. Jakarta. PT Elex Media Komputindo.

[11] CREMNET. (2000). Technology Brief No. 2 (Revised). Philippines : IRRI.

[12] Solichin, A. (2017, marc 19). Mengukur Kinerja Algoritma Klasifikasi dengan Confusion Matrix.

Available : https://achmatim.net/2017/03/19/mengukur-kinerjaalgoritma-klasifikasi-dengan-confusion-matrix/. 